\title{
MÚSICA NAS SOCIEDADES INDÍGENAS DAS TERRAS BAIXAS DA AMÉRICA DO SUL: ESTADO DA ARTE*
}

Rafael José de Menezes Bastos

\section{Apresentação}

A etnomusicologia das terras baixas da América do Sul, detentora de algumas das descrições mais antigas do mundo sobre "música primitiva" — as de Léry sobre canções tupinambá do Rio de Janeiro (de 1578 [veja 1980]) e Montoya sobre categorias do mundo sonoro-musical guarani (de 1639 [1876] $)^{1}$ — não conheceu desenvolvimento moderno comparável, mesmo que de longe, àquela que teve como palco regiões como a África subsaariana, a América do Norte e o sudeste asiático. O estudo das razões para que isto tenha acontecido não faz parte deste trabalho. Durante os últimos trinta anos, porém, essa área acadêmica passou por um crescimento significativo que parece ter perspectiva de continuidade, particularmente no Brasil. Esse crescimento expressou-se pela publicação de monografias e outros tipos de textos etnomusicológicos - ensaios, artigos e outros - e outras especializações que encontram na música tema relevante. ${ }^{2} \mathrm{O}$ quadro resultante de tais esforços é promissor, necessitando de análise na direção do desenho do perfil da música na região e da projeção de novas pesquisas.

Este texto, dividido em duas partes, busca aproximar esta tarefa, centrando-se na produção escrita, levando em conta, somente de passagem, as produções fonográfica, videográfica e similares. Na primeira parte, levanto as principais características da literatura produzida no período. Na segunda, considero algumas das marcas mais notáveis da música da região.

\section{$1^{\text {a }}$ parte - Principais características da literatura}

A etnomusicologia em referência tem como primeira característica a proveniência predominante do campo da etnologia. Explico: a etnomusicologia como 
um todo é produzida a partir basicamente das duas grandes áreas acadêmicas com tradição de formadoras da disciplina: antropologia e música, esta última através, de modo particular, da musicologia histórica (Menezes Bastos 1995). No caso da etnomusicologia sobre as músicas populares urbanas no Brasil, por exemplo, essa produção tem sido feita, de maneira mais ou menos equilibrada, a começar destas duas áreas - e, minoritariamente, de outras, entre as quais as de sociologia e história (Menezes Bastos 2005b). Porém, no caso da literatura sobre as músicas indígenas das terras baixas da América do Sul, nota-se que ela advém de forma predominante da etnologia, ${ }^{3}$ encontrando nos estudos sobre a mito-cosmologia, a filosofia, a lingüística, as artes como um todo, o ritual e o xamanismo, o simbolismo e a cognição, a história e a política algumas de suas principais portas de entrada. A investigação das razões deste quase monopólio etnológico sobre a etnomusicologia das terras baixas também não será objeto das presentes reflexões.

A segunda característica da produção etnomusicológica em foco é que ela freqüentemente como que recusa o rótulo "etnomusicologia", preferindo, na maioria das vezes, ser anunciada através de entradas como "antropologia da música", "antropologia musical" e outras. Valeria analisar esta espécie de evitação que, sugiro, teria a ver com o que acima chamei do quase monopólio da etnologia sobre a etnomusicologia em análise. Não farei isto aqui, porém. De qualquer sorte, originando-se os trabalhos daqui ou dali e tendo como etiqueta isto ou aquilo, o que parece estar constituído de maneira madura nos sistemas de ensino e pesquisa responsáveis pela produção aqui comentada - no Brasil, programas de pós-graduação em antropologia social — é o interesse pelas músicas indígenas como tema típico de investigação. Tudo se passa, então, com essa antropologia da música de forma similar ao que se dá, segundo Adorno (1983:259), com a sociologia da música: é ela uma das diversas antropologias sobre algo, em que este "algo" é a música.

A terceira característica da literatura comentada é que ela - como também aquela relativa à etnologia das terras baixas da América do Sul como um todo - está sendo produzida em instituições acadêmicas de vários países, envolvendo igualmente profissionais nacionais de países diversos. Isto concede uma importante marca internacional à etnomusicologia em análise. O Brasil, a França, a Grã-Bretanha e os Estados Unidos detêm em relação a este aspecto posição de destaque, o primeiro sendo o país onde, ao que parece, a literatura em foco é mais numerosa - particularmente a partir dos anos 1990 - mercê da produção cada vez mais abundante e expressiva dos programas de pós-graduação em antropologia social, que produzem dissertações de mestrado e teses de doutorado (veja Beaudet 1993, Menezes Bastos 2005a, Coelho 2007). ${ }^{4}$ 
A perspectiva comparativa, constituída desde o interior da própria etnografia, ${ }_{1}^{5}$ é a quarta característica da produção em consideração. Ela se sustenta na convicção teórico-metodológica, partilhada pelos americanistas de extrações as mais diferentes entre si, de que as terras baixas da América do Sul constituem um grande sistema relacional, comunicante inclusive com os Andes (tipicamente na longue durée). Este sistema relacional está assentado na existência de uma ampla rede de comunicações, na qual as artes e a artisticidade desempenham papéis absolutamente cruciais (Menezes Bastos 2001). Por artisticidade entende-se aqui um estado geral de ser, que envolve o pensar, o sentir, o fazer, na busca abrangente da "beleza", esta compreendida - para longe de suas formulações ocidentais consuetudinárias, tipicamente academicistas - tão somente como passe de ingresso nos universos da arte (tanto quanto a "monstruosidade", a "prototipicidade", a "eficácia", a "formatividade" e outras senhas). Esse estado geral, segundo os estudos tematicamente mais variados, cobrindo não apenas as áreas que o Ocidente consagrou como "belas artes", é uma característica marcante das culturas da região, para as quais, as coisas e os seres do mundo são (e constantemente vêm a ser) obras de arte. Isto desde a pessoa até o cosmo, passando de maneira ampla pela vida social (veja Overing 1989).

Vale apontar, por fim, que o reconhecimento, no período, do interesse pelos estudos etnomusicológicos nas terras baixas tem encontrado no nível político das relações das sociedades da região com o "mundo dos brancos" um importante fator: a musicalidade e a artisticidade em geral tão características desses povos têm sido, elas mesmas, importantes alavancas de sensibilização e solidariedade dos "civilizados" no sentido de sua arregimentação como aliados dos índios em suas lutas por cidadania. Consistente com esse quadro e apesar de ainda incipiente mas em ritmo de crescimento, os índios, com a ajuda de seus aliados, estão produzindo seus próprios discos e vídeos, assim como shows, espetáculos diversos e outros eventos (veja Mello 2003). ${ }^{6}$ Assim, a quinta característica da etnomusicologia das terras baixas da América do Sul no período ora em estudo tem uma grande carga de politicidade.

Como apontei desde o começo, o cenário atual da etnomusicologia das terras baixas da América do Sul é extremamente promissor. Se, por um lado, pode-se aqui contar com a existência de um número significativo de estudos, por assim dizer, inaugurais no período aqui enfocado - como os de Camêu (1977), Menezes Bastos (1999a [1978], 1990), Smith (1977), Beaudet (1997 [1977]), Travassos (1984), Aytai (1985), Fuks (1989), Hill (1993), Seeger (1987), Estival (1994), Olsen (1996) etc. — por outro, ele inclui, tipicamente no Brasil e a partir da segunda metade dos anos 1990, uma fértil floração de pesquisas realizadas por uma nova geração de etnomusicólogos, a maioria 
deles antropólogos. Entre estes estão os de Espinoza (1991), Salivas (1995), Silva (1997), Lima (1998), Montardo (2002), Piedade (1997, 2004), Mello (1999, 2005), Cunha (1999), Véras (2000), Werlang (2001), Dallanhol (2002), Coelho (2003), García (2005) e Herbetta (2006) ${ }^{7}$ e outros.

A existência dessa nova geração de etnomusicólogos sugere que a etnomusicologia em estudo parece ter ido além de sua fase de acumulação primitiva de capital, tornando possíveis sua reprodução e desenvolvimento. Espera-se com o trabalho da geração comentada a expansão da cobertura etnográfica da etnomusicologia em análise - ainda pequena, embora não tanto, conforme este texto pretende evidenciar - a abordagem da música com tematizações e aproximações teórico-metodológicas renovadas e o desenho de quadros comparativos articulados, regionais e sub-regionais.

No sentido de tornar ainda mais evidente a promissora situação da etnomusicologia em análise, anoto dois últimos pontos: a formação de uma quantidade cada vez mais expressiva de jovens antropólogos que, sem serem etnomusicólogos, estão realizando pesquisas de grande interesse para a compreensão da música nas terras baixas da América do Sul (veja Barbosa 1991, Ribeiro 1992, Oliveira Júnior 1998, Romano 2000, Arcanjo 2003, Cesarino 2003 e Gorham 2005), e a existência de materiais inéditos de grande interesse, publicados parcialmente em veículos de difícil acesso ou de circulação restrita. Aqui se incluem os estudos de Avery sobre os índios Mamaindé e Pareci (1973, 1974, 1973-1974, 1974-1975a, 1974-1975b) ${ }^{8}$ e os de Aytai sobre os Xetá e os Nambikwara (1978a, 1978b, 1978c, 1978d, 1979a, 1979b, 1979c, 1981a, 1981b, 1982a e 1982b). A abundância dessas referências sugere que elas constituem apenas a ponta de um iceberg muito maior e diversificado.

Para fechar a primeira parte deste texto, vale acrescentar que a etnomusicologia em estudo vem aparecendo em um número cada vez mais significativo de artigos nas coletâneas recentes sobre a etnomusicologia da América do Sul e da América Latina em geral (cf. Kuss 2004; Lühning e Rosa 2005; Lucas 1999; Lucas e Menezes Bastos 2000; Olsen e Sheehy 1998; Sandroni 2006; Tugny e Queiroz 2006). Quanto a intentos de comparação — no plano regional e naqueles sub-regionais - eles ainda são muito poucos e limitados. Entre eles estão os seguintes: Menezes Bastos (1996), tematizando as músicas dos índios Jê; Menezes Bastos e Piedade (1999), idem, dos Tupi-Guarani; Montardo (2002), idem dos Guarani. Há ainda os trabalhos sobre a região como um todo, a saber: Beaudet (1993) e o meu próprio (Menezes Bastos $1994,1999 b)$. Concluo sugerindo que tanto as bases quanto as perspectivas da etnomusicologia regional em consideração são sólidas. 


\section{$2^{\mathrm{a}}$ parte - Música nas terras baixas da América do Sul. Características notáveis}

Como disse anteriormente, as tentativas de comparação envolvendo as músicas das terras baixas da América do Sul são ainda muito poucas e limitadas, tanto nas escalas sub-regionais quanto na escala regional como um todo. Feitos na primeira parte do artigo o levantamento e a caracterização da literatura sobre a área, pretendo agora modestamente contribuir para a superação dessa limitação, apontando para e refletindo sobre as marcas que considero mais notáveis das referidas músicas e lançando algumas hipóteses de trabalho para pesquisas futuras. Vale salientar que, considerando a ainda relativamente pequena cobertura etnográfica da subárea de estudos embora, volto a considerar, significativa — as marcas em consideração têm o sabor de hipóteses de trabalho.

A primeira marca que considerarei, e sobre a qual tenho insistido em várias oportunidades (Menezes Bastos 1994, 1996, 1999b, 2001; Menezes Bastos e Piedade 1999), caracteriza o papel - e seu valor consensualmente visto como estratégico - desempenhado pela música na cadeia intersemiótica do ritual na região. A questão foi originalmente estudada em áreas das terras baixas, bem diferentes e afastadas umas das outras, por autores trabalhando de maneira independente: na Amazônia peruana, entre os Aruaque amuesha, por Smith (1977); e no Alto Xingu, por mim (1978 [1999a]), entre os xinguanos Tupi-guarani kamayurá. ${ }^{9}$ Smith caracteriza o papel da música na trama ritual amuesha como o de centro integrador dos discursos nela presentes, centro este que por assim dizer costura a unidade da expressão ritual a partir da diversidade existente entre os referidos discursos. Tudo se passa ali como se a música fosse o lugar centrípeto para onde convergem em sua diversidade - os discursos visuais, olfativos e de outros canais que compõem os ritos. A partir daí, esse lugar passa a ser centrífugo, recompondo a diversidade discursiva ritual. De forma similar, o caso kamayurá estabelece a música como um sistema pivot que intermedia, no rito, os universos das artes verbais (poética, mito) em relação àqueles das expressões plástico-visuais (grafismo, iconografia, adereços) e coreológicas (dança, teatro). Integração de um lado, intermediação de outro - envolvendo os diferentes canais (perdão pelo pleonasmo: em suas diferenças) discursivos - tais são os sentidos que, a partir dessas fontes dos anos 1970, tipificam o papel da música na cadeia intersemiótica do ritual da região em estudo.

Basso (1985), estudando os também xinguanos, mas Caribe kalapálo, enquanto confirma esses sentidos originais, afina-os: para ela, a natureza mesma da performance ritual é musical - daí seu importante conceito de 
ritual musical - a música constituindo a chave (key) da citada performance, desencadeando-a. ${ }^{10}$ Gebhart-Sayer $(1986,1987)$, abordando os Pano shipiboconibo da Amazônia peruana, leva adiante todos esses nexos. Para ela, entre a música e os desenhos visuais a relação é de tradução; no ritual xamânico desse povo, as canções são a tradução sonora, reversível, de motivos pictóricos. Assim, pode-se até dizer que estes seriam a transcrição visual daquelas, que são, portanto, sua partitura, notação musical (diga-se: non mensurata). Um nexo próximo a este parece fazer sentido entre os Caribe yekuana da Venezuela, envolvendo a cestaria e o canto (Guss 1990), tudo se passando entre esses índios como se compor cestas fosse cantá-las.

Em suma, é possível falar de uma generalidade do papel da música na cadeia intersemiótica do ritual nas terras baixas da América do Sul apontando para um lugar semântico que encompassa os nexos de integração, intermediação, desencadeamento e similares, sintetizáveis pelo nexo geral de tradução. Em 2001, sugeri que, neste contexto, o sentido de tradução salienta a relação semântica interdependente entre os subsistemas presentes na referida cadeia. Isto, entretanto,

[...] de forma antes tautegórica que alegórica, o que significa dizer que a referida tradução não deve ser pensada em termos sinonímicos ou da reprodução dos mesmos significados pelos diferentes subsistemas significantes. Não, pois estes subsistemas constituem, um a um, esforços de expressão significante de significados de outros canais, deslocando-os, no entanto, dos significados conseqüentes que mimeticamente produzem (:348).

Tal sentido de tradução aproxima-se daquele preconizado por Benjamin (1968), como "procura de ressonâncias e reverberações entre sistemas e códigos diversos, e de totalizações de pontos de vista parciais" (veja Carneiro da Cunha 1998:16).

A segunda característica notável da música nas terras baixas da América do Sul que abordarei pode receber o rótulo de seqüencialidade, e tipifica a organização musical dos rituais no plano intercancional, ou seja, no plano constituído pela articulação entre as respectivas canções (ou peças instrumentais ou voco-instrumentais) componentes. Recordo que Basso (1985:246253) identifica os ritos kalapálo como musicais, por entender que é através da performance musical que a comunicação é neles fabricada. No contexto desta identificação, a seqüencialidade em foco explicita-se pelo fato de os repertórios musicais da região - na grande maioria das vezes, parte de complexas cadeias intersemióticas, conforme foi abordado anteriormente organizarem-se em seqüências (ou seqüências de seqüências) de cânticos 
(sejam eles canções ou vinhetas), de peças instrumentais ou voco-instrumentais. Essas seqüências, assim como as seqüências de seqüências, freqüentemente ancoram a cronologia do dia e da noite e são por ela ancoradas. É possível que também o façam naquelas de outros ciclos temporais, como os meses, as estações etc., compondo calendários musicais.

Tudo leva a crer, então, que peças isoladas de música não parecem fazer muito sentido na região. Essa seqüencialidade no plano intercancional cujo tipo de organização evoca a da suíte ocidental (Fuller 2007) — foi primeiramente descrita por mim, de forma sistemática, entre os Tupi-guarani kamayurá do Alto Xingu (Menezes Bastos 1990, 1994, 1996a, 2004a, 2004b; Menezes Bastos e Piedade 1999). Posteriormente, ela foi estudada entre os Aruaque kulina do Acre (Silva 1997), os Tucano yepamasa (Piedade 1997), os Aruaque xinguano wauja (Piedade 2004; Mello 1999, 2005), os Tupi-guarani guaranis do sul e do centro-oeste brasileiros (Montardo 2002), os Caribe arara do Pará (Coelho 2003) e — sim, exatamente, sim - entre os "índios misturados" Kalankó de Alagoas (Herbetta 2006).

É minha hipótese de trabalho que este tipo de organização encontra-se muito mais disseminado do que a abrangência desta amostra dá a entender, apesar de a referida amostra ser, sem dúvida, considerável, embora eventualmente replicante, pois integrada somente por etnografias de minha autoria e de estudiosos que são ou foram meus alunos ou colaboradores.

Outras etnografias, em número significativo - não provenientes do círculo de Santa Catarina, nem fazendo parte de nenhum outro círculo, mas que envolvem grupos indígenas distantes e diversificados entre si - podem ser aqui enumeradas. Entre elas estão as de Beaudet (1997 [1977]): sobre os Tupi-guarani wayapi; Halmos (1979): Nambikwara; Aytai (1985): Jê xavante; Basso (1985) e Seeger (1987): Jê suyá; Estival (1994): Caribe arara; Cunha (1999): Pankararu — de novo, sim, "índios misturados". Tudo parece apontar para o fato de que a seqüencialidade apresenta-se como um dos rationales da organização dos rituais da região no plano intercancional. No sentido da consolidação dessa proposição, estudos circunstanciados sobre a temática estão na ordem do dia. No caso kamayurá por mim investigado, a seqüencialidade assume uma elaboração extremamente complexa, seguindo um padrão que chamei de estrutura seqüencial. Detalho um pouco, abaixo, este padrão, de grande interesse do ponto de vista cognitivo e que sugiro que, qua padrão, estará muito mais para típico do que para especial nas terras baixas (veja Menezes Bastos 1990, 2004a, 2004b).

A etnografia do ritual que abordei, o Yawari, é massiva, sendo ele um daqueles ritos - muito comuns nas terras baixas — de longa duração, cujas preliminares podem estar a anos de distância de sua execução propriamente dita. ${ }^{11}$ 
Já à primeira análise, porém, a citada etnografia exibe regularidades marcantes: o respectivo sistema cancional é um conjunto complexo de seqüências de seqüências de cânticos (canções ou vinhetas) composto pelas repetições feitas com mudanças maiores ou menores - das seqüências que o integram, repetições estas realizadas com a periodicidade do dia, durante 11 dias. As seqüências componentes repetem-se isonômica e isotopicamente, sendo variantes entre si. Chamo isonomia à relação de pertinência estrutural entre seqüências, que se caracterizam como transformações (no sentido de LéviStrauss) de uma estrutura (no caso, a estrutura seqüencial). ${ }^{12} \mathrm{Com}$ isotopia, refiro-me à sua localização numa idêntica parte do dia. Seqüências homólogas são aquelas ao mesmo tempo isonômicas e isotópicas. As mudanças referidas são ocasionadas por operações realizadas quando da reiteração da seqüência de referência de cada subconjunto de variantes. ${ }^{13}$ Então, canções ou vinhetas são incluídas, excluídas, substituídas, resseriadas, retrogradadas ou repetidas.

Como nuclídeos de certos elementos químicos, seqüências homólogas (excepcionalmente, seqüências quaisquer) trocam componentes entre si (cânticos), partículas livres (ou quase) que incorporam ou cedem. Noto que o sistema cancional do Yawari compõe-se de nove subconjuntos de seqüências homólogas - variantes entre si — que também chamo de cantos, no sentido de macrounidades de uma composição músico-poética de fôlego (o que evoca as epopéias mediterrâneas clássicas): noitinha (tipos abertura e regresso), noite, noite funda, madrugada, alta madrugada, clausura da madrugada e tarde (tipos de reabertura e continuação). Como para os Kamayurá o começo do dia se dá no crepúsculo, a noitinha é o primeiro canto do Yawari; a noite, o segundo, e assim por diante, até a tarde, sétimo e último canto.

O referido sistema cancional organiza-se, como disse, de acordo com um padrão que denomino estrutura seqüencial. Este pode ser visto tanto como um relato - uma "história" — quanto como um programa — "estrutura" de composição de seqüências (de cânticos [canções e vinhetas] e de seqüências de cânticos), administrando dois processos, repetição e diferenciação, tendo os cânticos como unidades de processamento. Daí resultam três tipos de sucessões: progressões, regressões e estagnações, que constituem, respectivamente, os tempos "futuro", "passado" e "presente". A estrutura seqüencial é do ponto de vista cognitivo uma máquina de ensinar (como a suíte e a sonata-forma ocidentais), no sentido de Minsky (1983), sendo, por outro lado, uma forma de agrupamento complexo (Snyder 2000:31-46) que opera com a memória de longo prazo (:69-71). Diferente da suíte ocidental, porém, ela não somente produz a progressão intercancional, mas também o retorno ou o regresso, assim como a estagnação - quando o tempo interno do rito é, ele mesmo, cancelado. Junto a isto, a memória que ela usa é tanto a de recognição ou identificação, quanto 
a de esquecimento ou apagamento ou, para evocar um texto magnífico: termo a termo, mármore $e$ - por que, não, ou — murta. ${ }^{14}$ Para tornar mais clara minha exposição, reflito a seguir sobre o primeiro canto do Yawari (noitinha) do tipo abertura. Eis a expressão de sua estrutura seqüencial, na qual a inclusão (I) de cânticos comanda $(\rightarrow)$ sua exclusão $(E) \cdot{ }^{15}$

Figura I - Expressão da estrutura seqüencial do primeiro canto (noitinha) do Yawari, tipo abertura (AB)

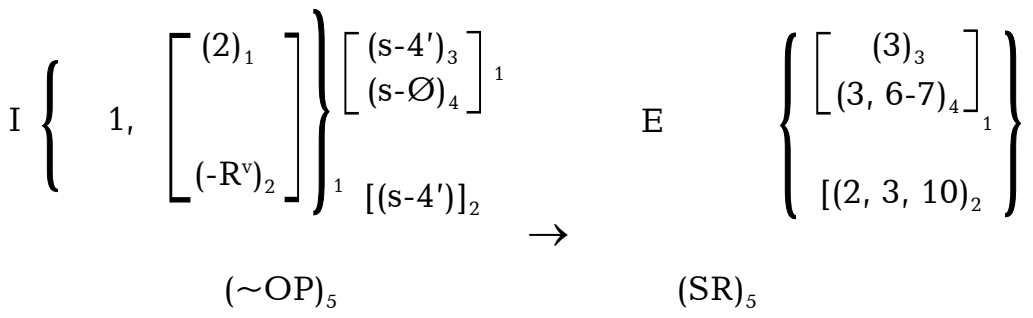

De acordo com esta expressão, a abertura (símbolo $\mathrm{AB}$ ) do sistema cancional do Yawari tem duas grandes alternativas, a saber:

$1^{\text {a }}$. Sua seqüência de referência $\left(\mathrm{SR}_{5}\right),{ }^{16}$ quando nenhuma $(\sim)$ operação (OP) é realizada com quaisquer de seus cânticos $\left(\sim \mathrm{OP}_{5}\right)$ [índice 5].

$2^{\mathrm{a}}$. Suas outras seqüências (que seguem a bifurcação sinalizada pelos índices 1 e 2).

Estas últimas são assim geradas: dependendo de a inclusão (I) se fazer entre os cânticos 1 e 2 ou 1 e $\left(-\mathrm{R}^{\mathrm{v}}\right)$ - $\mathrm{R}^{\mathrm{v}}$ sendo uma resseriação de cânticos há duas possibilidades de elementos a incluir (representadas pelos índices $2,3$ e 4$)$ :

$$
\begin{aligned}
& \cdot\left(\mathrm{s}-4^{\prime}\right) \\
& \cdot(\mathrm{s}-\varnothing)
\end{aligned}
$$

Nestas possibilidades, s é uma subseqüência de cânticos (1', 2' e 3') com alto grau de estabilidade, 4 ' é um cântico e $\varnothing$ sinaliza a ausência de cântico. Ambas as possibilidades apresentam combinação com a primeira escolha (índice 1). Porém, somente (s-4') combina com a segunda (índice 2).

Essas inclusões comandam $(\rightarrow)$ as exclusões (E), que são as seguintes:

- E (3) ${ }_{3}$ para a combinação de índice 1, subíndice 3, em que o 3 dentro do parênteses é outro cântico. 
- E (3,6-7) ${ }_{4}$ para a de mesmo índice (1) subíndice 4, em que 6-7 é a subseqüência dos cânticos 6 e 7 .

- E $(2,3,10)_{2}$ para a única combinatória possível de índice 2, em que 10 é outro cântico.

A expressão em análise, cuja escrita está feita em função das inclusões, pode ser comutada para uma outra expressão — tão válida como a primeira — elaborada em função das exclusões.

A terceira marca que comentarei da música nas terras baixas da América do Sul - que tenho chamado de estrutura núcleo-periferia - caracteriza os tipos de relação entre os indivíduos e os grupos de executantes formadores dos conjuntos musical-coreográficos (solo, coro etc.). De começo, vale notar que esta característica não é puramente musical, sendo também fortemente coreológica, ou seja, ligada à dança. ${ }^{17}$ De acordo com meus estudos sobre a música e a dança xinguanas (Menezes Bastos 1990, 1994, 1996, 1999b), a relação entre os indivíduos e os grupos de executantes constituintes dos conjuntos musical-coreográficos nas terras baixas é complexa, não se reduzindo, por exemplo, aos dois termos sucessivos e alternantes da forma antifonal (solo e coro), tão comum em tantas partes do planeta, por exemplo, na África subsaariana e no Ocidente (Lomax 1968).

A estrutura núcleo-periferia constitui-se da relação — em sucessão e/ou simultaneidade - entre o que denomino núcleo e o que chamo de periferia. O primeiro é composto por um ou uma solista (ou mestre/a de música) e seus ou suas ajudantes; o segundo pelos demais executantes (masculinos ou femininos). No núcleo - integrado por adultos maduros - o mestre ou a mestra entra via de regra sozinho/a com o caput de cada canção ou vinheta, ao final do qual é seguido/a pelos ajudantes, que o/a mestre/a repete tipicamente em heterofonia. ${ }^{18}$ Enquanto isto, o mestre ou a mestra continua com seu canto. Este núcleo canta, na grande maioria das vezes, canções, aqui e ali intermediadas por vinhetas, que são configurações músico-lingüísticas geralmente onomatopaicas com alto grau de estabilidade.

A periferia, por outro lado - integrada por adultos jovens, adolescentes e crianças - emite onomatopéias com maior ou menor estabilidade músicolingüística e/ou as improvisa, constituindo-se em um amplo tecido polifônico. O núcleo e a periferia, no caso xinguano por mim abordado, são irredutíveis entre si, embora integrantes, sem dúvida, de um todo. Sua relação, que evoca a da gemelaridade ameríndia, uma dualidade assimétrica (Lévi-Strauss 1993; Menezes Bastos 1996), é dada pelo fato de que ambos dramatizam, à sua maneira - através, respectivamente, da canção e da onomatopéia músico-lingüística — os mitos que estão na base dos ritos. 
A estrutura núcleo-periferia pode assumir formas variadas, pela multiplicação e/ou pelo cancelamento de seus termos. Desta maneira, as formas em solo individual, as que são configuradas por muitos solos individuais (caso da akia suyá [veja Seeger 1987]), assim como aquelas em coro (como a ngere, também suyá) e outras podem ser vistas como suas variações. Nas variações citadas, a periferia deixa de existir: na primeira, o núcleo reduzindo-se ao solo; na segunda, este — também sem coro - multiplicando-se; na terceira, fazendo-se presente somente o coro, sem o solo.

Do ponto de vista coreográfico, a estrutura em foco, com suas variações, encontra nas formações em linha, fila (procissão), cunha e bloco algumas de suas disposições mais comuns. Conforme antes salientado, a terceira característica da música na região em estudo tem uma forte realidade coreológica, sinal de que a dança, tanto quanto a música e os demais nodos da cadeia intersemiótica do ritual, é um domínio de interesse também estratégico para a compreensão da região. Noto que no caso xinguano (Menezes Bastos 1990, 2001; Véras 2000), a dança manifesta-se desde o discurso nativo, como último redutor da referida cadeia intersemiótica, espécie de limite desta, para além do qual nada mais pode existir.

A terceira característica da música na região das terras baixas da América do Sul, sistematicamente descrita em meus trabalhos sobre a música e a dança xinguanas, parece ter também largo espectro, espraiando-se do noroeste e do nordeste amazônicos (Piedade 1997; Beaudet 1997) até o sul das terras baixas (Montardo 2002); do nordeste brasileiro (Cunha 1999; Herbetta 2006) até o sudeste e o sudoeste da Amazônia (Smith 1977; Silva 1997; Werlang 2001), passando por muitas sub-regiões do interior amazônico (conforme os casos estudados por Coelho 2003; Mello 2005; Seeger 1987; Véras 2000, além de outros).

A quarta marca relevante da música nas terras baixas da América do Sul tipifica o processo predominante na região de composição de peças musicais: a variação. Nesse processo, o material temático — tipicamente os motivos $^{19}$ - exposto via de regra no caput das peças, é elaborado através de vários procedimentos, entre os quais os de repetição, aumentação, diminuição, transposição, retrogradação e outros, as transformações daí resultantes guardando as características essenciais daquele material. ${ }^{20}$ Essa característica é muito disseminada na região, espalhando-se desde o norte amazônico (Piedade 1997; Beaudet 1997) até o sul do continente (Montardo 2002); do nordeste brasileiro (Cunha 1999; Herbetta 2006) ao sul da Amazônia (Silva 1997; Werlang 2001), alcançando muitas subáreas interiores da região. Para maior aprofundamento da questão, conferir, entre muitos outros, os estudos de Avery (1977); Halmos (1979); Aytai (1985, 1978a-d, 1979a-c); Travassos 
(1984); Seeger (1987); Menezes Bastos (1990); Véras (2000); Werlang (2001); Coelho (2003); Piedade (2004); Mello (2005).

Os estudos detalhados de Menezes Bastos (1990, 2004a, 2004b [Kamayurá]), Piedade (2004) e Mello (2005) [Wauja] lançam luz sobre como o processo de variação está na base da composição musical em nível intracancional entre os xinguanos. No caso da música vocal kamayurá, o que chamei de diadismo diatônico é um dos procedimentos mais comuns de geração de motivos, a díade diatônica sendo nele constituída tipicamente pelas notas que perfazem um salto de terça. Este é o caminho por excelência, entre os Kamayurá, de construção do centro tonal de uma peça, ascendente ou descendente, preferencialmente menor (maior costuma ser bem mais raro). Assim gerado o motivo inicial da peça, as variações que dele são feitas em seguida, formando sentenças e períodos, usualmente administram o processo que denominei de serialismo cromático, no qual o motivo (ou a série) original é variado por preenchimento cromático paulatino, o que pode resultar na composição de motivos derivados completamente cromáticos.

Entre os Wauja, Piedade (2004) mostra com brilhantismo e rigor, ao estudar a música instrumental, como a variação motívica é o cerne do processo de composição da música das chamadas "flautas sagradas". Os motivos entendidos não necessariamente como segmentos mínimos - são ali de dois tipos: motivos-de-tema e motivos-de-toque, compreendidos, respectivamente, como as assinaturas das peças individuais e das suítes (seqüências) das quais elas fazem parte $(: 150)$. Entre os princípios variacionais, o autor anota os de aumentação, diminuição, transposição, inversão e muitos outros (:201). Ainda entre os Wauja, Mello (2005) evidencia como o processo de variação descrito por Piedade para a música instrumental masculina tem também vigência na música vocal feminina. Por outro lado, consolidando análises que começaram em seu texto de 1999, Mello (2005:9-11) vai demonstrar — com base em elegante exame musicológico - como parte dos repertórios masculino e feminino wauja, tipicamente os das ditas "flautas sagradas" e os do ritual feminino do Amurikumã, rigorosamente falando, são variantes entre si, tudo se passando entre esses Aruaque como se as mulheres cantassem transposições vocais das músicas das flautas em foco, os homens fazendo o inverso, executando à flauta as músicas femininas vocais. ${ }^{21}$

Em outras palavras, o processo de variação atravessa aqui os gêneros musicais (e "sexuais"). Além de a variação distinguir o processo de composição intracancional na região, ele também parece marcá-lo no plano intercancional, aquele das seqüências, conforme o anteriormente estudado. Neste sentido, cada uma das seqüências integrantes de um mesmo universo de seqüências é, via de regra, variante da seqüência de referência. 


\section{Considerações finais}

Como disse no início deste texto, a situação atual dos estudos sobre a música nas sociedades indígenas das terras baixas da América do Sul — tema típico e não especial da etnologia respectiva - é extremamente promissora. Embora a cobertura etnográfica disponível sobre o assunto seja ainda pequena, mas de forma alguma irrelevante, ${ }^{22}$ como apontei, ela permite o levantamento de um perfil geral da música na região, básico para a projeção de pesquisas futuras. O presente balanço levantou quatro marcas fundamentais quanto ao desenho desse perfil. De começo, o papel da música na cadeia intersemiótica do ritual apontando para o sentido geral de tradução. Trata-se de um papel consensualmente visto como de grande interesse, que deve ser abordado, porém, como tarefa a encarar e não como motivo jactante e paralisante de intelectual paroquiano. Em seguida, propus que a seqüencialidade constitui, na região, um dos rationales da organização dos rituais no plano intercancional, ou seja, no plano composto pela articulação entre as peças de música (vocal, instrumental, voco-instrumental) dos respectivos sistemas cancionais.

A obviedade da compreensão da música como "arte do tempo" — leia-se da memória como recognição - aqui deve ser superada pela inquirição sobre a articulação entre o referido tipo de memória e aquele do esquecimento. A estrutura núcleo-periferia, com suas variações - ou seja, transformações aparece em terceiro lugar no balanço aqui feito, ancorando a compreensão das complexas relações que envolvem os elementos constituintes dos conjuntos musicais na região. Tudo aqui não se resume à alternação entre solo e coro, mas a relação da irredutibilidade entre as partes também se manifesta como absolutamente fundamental. A estrutura comentada sinaliza que a dança - tanto quanto a música e os demais nodos da cadeia intersemiótica do rito - é um domínio de interesse estratégico para a compreensão da região. Esta é uma dança, entretanto, na qual convivem as tendências catabática - orientada para a terra e com gosto pelo peso - e acrobática voltada para o ar, em busca da "liberdade", dir-se-ia.

Como quarta e última marca, o presente estudo apontou a variação como processo básico de composição musical na região, nos planos intracancional, referente às peças musicais e intercancional, atinente às suas seqüências. Observe-se que a idéia de variação aqui adotada simplesmente não descarta a de desenvolvimento (vide nota 23). Sugiro que pesquisas intensivas e extensivas sobre estes quatro pontos estão na ordem do dia no sentido do avanço dos conhecimentos setorial — sobre a música - e geral — sobre a etnologia das terras baixas da América do Sul. 
Evidentemente que outros tópicos deverão ser investigados na direção do avanço em comentário como, por exemplo, até que ponto serão pertinentes para o campo musical os divisores lingüístico-culturais, de tal forma que se possa falar de maneira consistente em paisagens musicais tupi, jê, aruaque, caribe e outras (Beaudet 1993:527)? Qual o impacto do contato com o "mundo dos brancos" sobre os sistemas musicais ameríndios, levando-se em conta aquilo que os casos dos índios ditos "misturados" Pankararu (Cunha 1999) e Kalankó (Herbetta 2006) parecem evidenciar? Por fim, o achado de Silva (1999) entre os Aruaque kulina — relativo à localização no cantar dos grilos da pulsação da música de um ritual dos humanos. Este fato tem um interesse meramente local, ou sugere algo mais disseminado, eventualmente uma outra marca da música das sociedades indígenas das terras baixas da América do Sul, ligada à incorporação, na música dos humanos, de elementos sonoro-musicais provindos da natureza?

Recebido em 20 de maio de 2007

Aprovado em 21 de agosto de 2007

Rafael Menezes Bastos é professor do Departamento de Antropologia da Universidade Federal de Santa Catarina. E-mail: <rafael.bastos@pesquisador. cnpq.br>.

\section{Notas}

- Uma versão anterior deste texto saiu em duas partes (veja Menezes Bastos 2006a e 2006b). Obrigado a Carlos Sandroni pelas dicas bibliográficas, e aos pareceristas anônimos comissionados por Mana pelas sugestões visando à presente versão.

1 Sobre o primeiro livro - que Cooley (1997:6) considera ser a primeira descrição etnomusicológica baseada em trabalho de campo realizada no mundo - veja Azevedo (1941), Camêu (1977) e Veiga (1981). Para uma leitura etnomusicológica do Tesoro de Montoya, veja Montardo e Martins (1996) e Montardo (2002:220). Sobre as duas obras, veja Menezes Bastos e Piedade (1999).

2 Entre as monografias etnomusicológias, veja Menezes Bastos (1999a [1978], 1990), Halmos (1979), Aytai (1985), Seeger (1987), Ermel (1988), Hill (1993), Estival 
(1994), Olsen (1996), Beaudet (1997 [1977]), Werlang (2001), Montardo (2002), Piedade (1997, 2004), Mello (1999, 2005) e García (2005). Entre as outras, Hugh-Jones (1979), Basso (1985), Viveiros de Castro (1986), Graham (1995), Pinto (1997), Velthem (2003). Veja Aretz (1991), Beaudet (1993), Menezes Bastos (1994, 1999b e 2005a), Blasco (2000) e Coelho (2007) para alguns levantamentos.

${ }^{3}$ Pereira (1995), Magalhães (1994), Nascimento (1998) e Barros (2003) são algumas das exceções a essa tendência, a primeira proveniente da área de comunicação e semiótica, as três últimas da área de música. Cf. Higuita (2004) para um trabalho originário da área da lingüística.

${ }^{4}$ Entre os programas brasileiros de pós-graduação em antropologia social, o da Universidade Federal de Santa Catarina ocupa posição de destaque a este respeito. Veja o site do MUSA (http://musa.ufsc.br), sua entrada no Diretório dos Grupos de Pesquisa do CNPq (http://www.cnpq.br) e os resumos de dissertações de mestrado e teses de doutorado no Banco de Teses da CAPES (http://www.capes.gov.br). Nos últimos quinze, vinte anos, as etnomusicologias americana, inglesa e francesa envolvendo a América do Sul indígena têm privilegiado as terras altas. Obrigado a Anthony Seeger, Jean-Pierre Chaumeil, Jean-Michel Beaudet e Henry Stobart por me ajudarem a consolidar este ponto. Outros países da América Latina exibem uma literatura sobre o tema em estudo cada vez mais significativa. Entre eles, a Argentina (veja García 2002, 2005; Novati 1984), a Colômbia (Blasco 2000; Higuita 2004; Melo 2005) e a Bolívia (Sánchez 1998, 2001).

${ }^{5}$ Viveiros de Castro (2002:121) chamou esta perspectiva de "comparativismo imanente".

${ }^{6}$ Veja o site do Instituto Socioambiental (http://www.socioambiental.org/), na parte referente aos povos indígenas, para informações relativas ao Brasil, sobre CDs e vídeos. Também o da organização "Vídeo nas Aldeias" (http://www.videonasaldeias. org.br/), para o programa de mesmo nome envolvendo autoria indígena. Sobre a questão da apropriação indígena da produção fonográfica e de vídeos, cf. Gallois e Carelli (1995), Turner (1993), Menezes Bastos (2002) e Coelho (2004).

${ }^{7}$ Note-se que muitos dos integrantes da geração em foco estão ainda em fase de formação doutoral (veja, por exemplo, Barros [em andamento] e Lourenço 2006).

${ }^{8}$ Deste missionário do Summer Institute of Linguistics, somente tenho conhecimento de um texto publicado sobre as terras baixas da América do Sul: o de 1977.

${ }^{9}$ Recordo que meu livro de 1978 (veja 1999a) transcreve ipsis litteris a dissertação de mestrado que defendi na Universidade de Brasília em 1976.

${ }^{10}$ Para chegar a esta fina síntese, Basso realiza um estudo de grande interesse sobre a arte verbal kalapálo, abordando de maneira sensível sua musicalidade. Para outras obras referenciais que têm nessa musicalidade um de seus temas fortes, veja Sherzer e Urban (1986) e Franchetto $(1993,2000)$. 
${ }^{11}$ O Yawari é um ritual funerário, desencadeado pelo falecimento daquele a quem se comemora e "co-esquece" (pois os Kamayurá nele investem tanto a memória de recordação quanto a de esquecimento). O rito que estudei em 1981 teve seus preliminares em uma morte acontecida em 1977 (veja Menezes Bastos 1990, 2004a, 2004b). Mello (2005) estuda, entre os xinguanos Aruaque wauja, ritos cujos desencadeamentos datam de dez anos passados em relação às suas execuções presentes.

${ }^{12}$ Com base em Lévi-Strauss (1980 [1952]), entendo a noção de estrutura como construção abstrata que evidencia as regras de constituição de um dado universo de fenômenos. Para seu conceito de transformação, conferir o mesmo texto.

${ }^{13}$ Seqüência de referência é aquela que ocorre de primeiro nas reiterações de uma determinada seqüência de seqüências de cânticos, no caso do Yawari. A noção claramente inspira-se na de mito de referência de Lévi-Strauss (1991 [1964]).

${ }^{14}$ Veja Estival (2006) para um estudo sobre a questão da memória musical entre os Ayoré do Chaco.

${ }^{15}$ Como na álgebra elementar, na leitura desta expressão as chaves ( \{\}$)$ são hierarquicamente superiores aos colchetes ([]), estes o sendo aos parênteses (()). Na expressão, os cânticos são representados pelos algarismos de 1 a 10 e de 1' a 4'. Estes quatro últimos cânticos não se manifestam na SR, sendo incluídos em reiterações suas.

${ }^{16}$ A SR é formada por 10 cânticos — entre canções e vinhetas — representados pelos algarismos de 1 a 10. A AB como um todo é composta por 14 cânticos, aqueles que compõem a subseqüência de 1' a 4' devendo ser somados aos 10 da SR.

17 Uma dança, porém, como mostrou Véras (2000) estudando os xinguanos Caribe matipú, na qual convivem as tendências catabática - em direção à terra, ao chão - e acrobática - para o ar, para cima.

${ }^{18}$ Brevemente falando, heterofonia é a variação simultânea de uma melodia.

${ }^{19}$ Uso o conceito de motivo de Lidov (1975), vendo-o como o segmento mínimo do estrato sintático.

${ }^{20}$ Para o processo de variação, veja Randel (1978:533-535). Segundo Rosen (1994:86-87), ele tem o desenvolvimento como oposto polar; neste, as transformações resultantes diferenciam-se da/s idéia/s original/is pela interveniência de nova/s idéia/s. Essa diferenciação entre a variação e o desenvolvimento é problemática, particularmente nos termos do conceito schoenbergiano de variação progressiva, compreendida como processo gradual de desenvolvimento motívico (Dudeque 2005:228).

${ }^{21}$ Aí certamente está o nexo da prescrição auditiva às mulheres em relação à música das "flautas sagradas", vis-à-vis à sua proibição visual.

${ }^{22}$ Sobre a diferenciação feita por Popper entre a "abundância do conhecido e o ilimitável do desconhecido", cf. o célebre comentário de Adorno (1986). 


\section{Referências bibliográficas}

ADORNO, Teodor. 1983. "Idéias para a sociologia da música". In: P. E. Arantes (org.), Benjamin, Habermas, Horkheimer, Adorno. São Paulo: Abril Cultural. Coleção Os Pensadores. pp.259-268. 1986. "Sobre a lógica das ciências sociais". In: G. Cohn (org.), Sociologia: Theodor W. Adorno. São Paulo: Ática. pp. 46-61.

ARCANJO, Jozelito Alves. 2003. Toré e identidade étnica: os Pipipã de Kambixuru (índios da Serra Negra). Dissertação de mestrado em antropologia, Universidade Federal de Pernambuco, Recife.

ARETZ, Isabel. 1991. Música de los aborígenes de Venezuela. Caracas: Fundef/ Conac.

AVERY, Thomas L. 1973. "Relatório de dados etnomusicológicos" (referente a uma visita à aldeia Tanorehana, Parecí) Ms. . 1974. "Mamaindé music transcriptions, 1973/1974". Brasília: Summer Institute of Linguistics. Ms. .1973-1974. "Mamaindé music analysis". 3 vols. Brasília: Summer Institute of Linguistics. Ms.

.1974-1975a . "Mamaindé vocal music". Brasília: Summer Institute of Linguistics. Ms. 42pp.

.1974-1975b. "Mamaindé vocal music". Brasília: Summer Institute of Linguistics. Ms. (em carimbo: "análise provisória"). 31pp.

. 1977. "Mamaindé vocal music". Ethnomusicology, 21(3):359-377.

AYTAI, Desidério. 1978a. "Um microcosmo musical: cantos dos índios Xetá" (1). Publicações do Museu Municipal de Paulínia, 3:1-8.

1978b. "Um microcosmo musical: cantos dos índios Xetá" (2). Publicações do Museu Municipal de Paulínia, 4:1-9.
. 1978c. "Um microcosmo musical: cantos dos índios Xetá" (3). Publicações do Museu Municipal de Paulínia, 5:1-17.

. 1978d. "Um microcosmo musical: cantos dos índios Xetá" (4). Publicações do Museu Municipal de Paulínia, 6:1-17.

. 1979a. "Um microcosmo musical: cantos dos índios Xetá" (5). Publicações do Museu Municipal de Paulínia, 8:13-19. . 1979b. "Um microcosmo musical: cantos dos índios Xetá" (6). Publicações do Museu Municipal de Paulínia, 9:9-21. 1979c. "Um microcosmo musical: cantos dos índios Xetá" (7). Publicações do Museu Municipal de Paulínia, 10:15-22. . 1981a. "A flauta nasal nambikuara" (1). Publicações do Museu Municipal de Paulínia, 17:6-17. . 1981b. "A flauta nasal nambikuara" (2). Publicações do Museu Municipal de Paulínia, 18:11-26. 1982a. "A flauta nasal nambikuara" (3). Publicações do Museu Municipal de Paulínia, 19:12-19. 1982b. "A flauta nasal nambikuara" (4). Publicações do Museu Municipal de Paulínia, 20:8-16.

1985. O mundo sonoro xavante. Coleção Museu Paulista, Etnologia, vol. 5 . São Paulo: Universidade de São Paulo. AZEVEDO, Luiz Heitor C. de. 1938. Escala, ritmo e melodia dos índios brasileiros. Rio de Janeiro: Tipographia do Jornal do Comércio.

. 1941. "Tupinambá melodies in Jean de Léry's 'Histoire d'un voyage faict en la terre du Brésil'". In: Papers of the American Musicological Society, Annual Meeting, pp. 85-96. 
BARBOSA, Wallace de Deus. 1991. Os índios Kambiwá de Pernambuco: arte e identidade étnica. Dissertação de mestrado em belas artes, UFRJ, Rio de Janeiro.

BARROS, Liliam Cristina da Silva. 2003. Música e identidade indígena na festa de Santo Alberto: São Gabriel da Cachoeira, Alto Rio Negro, AM. Dissertação de mestrado em música, Universidade Federal da Bahia, Salvador. Música e identidade indígena na festa de Santo Alberto: preservação e mudança na criação de um acervo da comunidade do Bairro da Praia. Tese de doutorado em música (em andamento; início em 2003). Universidade Federal da Bahia, Salvador.

BASSO, Ellen B. 1985. A musical view of the universe: kalapalo myth and ritual performances. Philadelphia: University of Pennsylvania Press.

BEAUDET, Jean Michel. 1993. "L' ethonomusicologie de l' Amazonie". L' Homme, 126-128:527-533. 1997 [1977]. Souffles d' Amazonie: les orchestres «Tule» des Wayãpi. (Collection de la Société Française D' Ethnomusicologie, III). Nanterre: Société d' Ethnologie.

BENJAMIN, Walter. 1968. "The task of the translator: an introduction to the translation of Beaudelaire's 'Tableaux parisiens'". In: Illuminations. New York: Schoken Books. pp. 69-82.

BLASCO, Carlos M. 2000. "Entre el folklore y la etnomusicologia: 60 años de estudios sobre la música popular tradicional en Colombia". Contratiempo - Revista de Música en la Cultura, 11:36-49.

CAMÊU, Helza. 1977. Introdução ao estudo da música indígena brasileira. Rio de Janeiro: Conselho Federal de Cultura.

CARNEIRO DA CUNHA, Manuela. 1998. "Pontos de vista sobre a floresta amazônica: xamanismo e tradução". Mana. Estudos de Antropologia Social, 4(1):7-22.

CESARINO, Pedro de N. 2003. Palavras torcidas, metáfora e personificação nos cantos xamanísticos ameríndios. Dissertação de mestrado em antropologia social, PPGAS/ Museu Nacional/ UFRJ, Rio de Janeiro.

COELHO, Luis Fernando Hering. 2003. Para uma antropologia da música arara (Caribe): um estudo do sistema das músicas vocais. Dissertação de mestrado em antropologia social, Universidade Federal de Santa Catarina, Florianópolis. 2004. "Música indígena no mercado: sobre demandas, mensagens e ruídos no (des)encontro intermusical". Campos, 5:151-166. 2007. "A nova edição de Why Suyá Sing, de Anthony Seeger, e alguns estudos recentes sobre música indígena nas terras baixas da América do Sul". Mana. Estudos de Antropologia Social, 13(1):237-249.

COOLEY, Timothy J. 1997. "Custing shadows in the field: an introduction". In: F. Barz \& T. J. Cooley (orgs.), Shadows in the field: new perspectives for fieldwork in ethnomusicology. New York/ Oxford: Oxford University Press. pp.1-19.

CUNHA, Maximiliano Carneiro da. 1999. A música encantada pankararu - toantes, torés, ritos e festas na cultura dos índios Pankararu. Dissertação de mestrado em antropologia cultural, Universidade Federal de Pernambuco, Recife.

DALLANHOL, Kátia Maria B. 2002. Jeroky e Jerojy: por uma antropologia da música entre os Mbyá-Guarani de Morro dos Cavalos. Dissertação de mestrado em antropologia social, Universidade Federal de Santa Catarina, Florianópolis. 
DUDEQUE, Norton. 2005. "Aspectos do academicismo germânico no primeiro movimento do Quarteto n. 3 de Alberto Nepomuceno". Ictus, 6:211-232.

ERMEL, Priscilla Barrak. 1988. O sentido mítico do som: ressonâncias estéticas da música tribal dos índios Cintalarga. Dissertação de mestrado em antropologia social, Pontifícia Universidade Católica, São Paulo.

ESPINOZA, Birgitta Leduc de. 1991. Les chants magiques achuar et leurs avatars instrumentaux. Paris: Université Paris X - Nanterre. Memória de DEA.

ESTIVAL, Jean-Pierre. 1994. Musiques instrumentales du Moyen Xingu et de l' Iriri (Brésil). Tese de doutorado em antropologia social, Université de Paris X, Nanterre.

2006: "Memória, emoção, cognição nos cantos Irade dos Ayoré do Chaco Boreal". Mana. Estudos de Antropologia Social, 12(2):315-332.

FRANCHETTO, Bruna. 1993. "A celebração da história nos discursos cerimoniais kuikuro (Alto Xingu)". In: M. Carneiro da Cunha \& E. viveiros de Castro (orgs.), Amazônia: etnologia e história indígena. São Paulo: Núcleo de História Indígena e do Indigenismo da USP/ Fapesp. pp. 95-116.

2000. "La parole du chef: rencontres rituels dans le Haut Xingu". In : A. Monod-Becquelin \& P. Erikson (orgs.), Les rituels du dialogue: promenades ethnolinguistiques en terres amérindiennes. Nanterre: Societé d'Ethnologie, 99. pp. 481-510.

FUKS, Victor. 1989. Demonstration of multiple relationships between music and culture of the Waiãpi indians of Brazil. Tese de doutorado em antropologia social, Indiana University, Bloomington.

FULLER, David. 2007. "Suite". In: L. Macy (org.), Grove music online. http://www. grovemusic.com. Acesso em 07/04/2007.
GALLOIS, Dominique T. \& CARELLI, Vincent. 1995. "Diálogo entre povos indígenas: a experiência de dois encontros mediados pelo vídeo". Revista de Antropologia, 38(1):205-259.

GARCÍA, Miguel A. 2002. "Making culture coherent: nomadism, 'Open Agenda' and music in Wichi society ". Yearbook for Traditional Music, 34:47-65.

2005. Paisajes sonoros de un mundo coherente. Prácticas musicales en la sociedad Wichí. Buenos Aires: Instituto Nacional de Musicologia. GEBHART-SAYER, Angelika. 1986. "Una terapia estética. Los diseños visionários de ayahuasca entre los Shipibo-Conibo". América Indígena, 46(1):189-218.

1987. Die Spitze des Bewusstseins. Untersuchungen zu Weltbild und Kunst der Shipibo-Conibo. Hohenschäftlarn: Klaus Renner Verlag.

GORHAM, Jeffrey Scott. 2005. Sonhos e cantos indígenas. Exemplos de poder xamanístico sul-americano. Dissertação de mestrado em antropologia social, Universidade de Brasília.

GRAHAM, Laura R. 1995. Performing dreams: discourses of immortality among the Xavante of Central Brazil. Austin: University of Texas Press.

GUSS, David M. 1990. To weave and sing: art, symbol, and narrative in the South American rainforest. Berkeley/ Los Angeles: University of California Press.

HALMOS, Istvan. 1979. "The music of Nambicuara indians (Mato Grosso, Brazil)". Acta Ethnographica Academiae Scientiarum Hungaricae, 28:205-350.

HERBETTA, Alexandre Ferraz. 2006. O "idioma" kalankó: por uma etnografia da música no Alto-Sertão alagoano. Dissertação de mestrado em antropologia social, Universidade Federal de Santa Catarina, Florianópolis. 
HILL, Jonathan. 1993. Keepers of the sacred chants: the poetics of ritual power in an amazonian society. Tucson: University of Arizona Press.

HIGUITA, Jesús M. Girón. 2004. Recuperación de cantos de baile de la etnia Puinave del Departamento del Guainía. Bogotá: Universidad de los Andes.

HUGH-JONES, S. 1979. The palm and the pleiades: initiation and cosmology in northwest Amazonia. Cambridge: Cambridge University Press.

KUSS, Malena. 2004. Music in Latin América and the Caribbean: an encyclopedic History. vol.1. Austin: University of Texas Press.

LÉRY, Jean de. 1980 [1578]. Viagem à terra do Brasil. Belo Horizonte: Itatiaia.

LÉVI-STRAUSS, Claude. 1980 [1952]. "A noção de estrutura em etnologia". In: M. Chauí (org.), Os pensadores: LéviStrauss. São Paulo: Abril. pp.1-43. 1991 [1964]. O cru e o cozido (Mitológicas I). São Paulo: Brasiliense.

1993 [1991]. "A ideologia bipartida dos ameríndios". In: História de lince. São Paulo: Companhia das Letras. pp.204-217.

LIDOV, David. 1975. On musical phrase. Montreal: Université de Montreal.

LIMA, Ana Paula Ratto de. 1998. Traços nômades: rítmicas da música ameríndia. Dissertação de Mestrado em Antropologia Social, PPGAS/ Museu Nacional/ UFRJ, Rio de Janeiro.

LOMAX, Alan. 1968: Folk song style and culture. Washington: American Association for the Advancement of Science.

LOURENÇO, Sonia Regina. 2006. Adança dos Aruanãs: rito, mito e música entre os Javaé da Ilha do Bananal - TO. Projeto de tese de doutorado em antropologia social, Universidade Federal de Santa Catarina, Florianópolis.
LUCAS, Maria Elizabeth (org.). 1999. "Música e sociedade". Horizontes Antropológicos, 11.

\& MENEZES BASTOS, Rafael José de (orgs.). 2000. Pesquisas recentes em estudos musicais no Mercosul. Porto Alegre: Programa de Pós-Graduação em Música (Série Estudos, 4).

LÜHNING, Ângela Elisabeth \& ROSA, Laila C (orgs.). 2005. Etnomusicologia: lugares e caminhos, fronteiras e diálogos. Anais do $2^{\circ}$. Encontro Nacional da Associação Brasileira de Etnomusicologia. Salvador: Contexto.

MAGALHÃES, Luiz César Marques. 1994. A música do povo calado: um estudo do Toré Kiriri. Dissertação de mestrado em música, Universidade Federal da Bahia, Salvador.

MELLO, Maria Ignez Cruz. 1999. Música e mito entre os Wauja do Alto Xingu. Dissertação de mestrado em antropologia social, Universidade Federal de Santa Catarina, Florianópolis. .2003. "Arte e encontros interétnicos: a aldeia wauja e o planeta". Antropologia em Primeira Mão, 54:4-23. 2005. Iamurikuma: música, mito e ritual entre os Wauja do Alto Xingu. Tese de doutorado em antropologia social, Universidade Federal de Santa Catarina, Florianópolis

MELO, Nelsa J. De la Hoz. 2005. Baile de tusi, de la boa al arco iris: rito, relaciones sociales e identidad de la etnia Andoke, Medio Rio Caquetá, Amazonía Colombiana. Bogotá: Universidad de los Andes.

MENEZES BASTOS, Rafael José de. 1990. A festa da jaguatirica: uma partitura crítico-interpretativa. Tese de doutorado em antropologia, Universidade de São Paulo.

1994. "Aspects of music in Amazonia: comparative perspectives from the study of kamayurá music (Apùap/ 
Upper-Xingu)". Paper presented in the $48^{\text {th }}$ International Congress of Americanists (Stockholm/Uppsala, July 4-9, 1994), Symposium: Music in Native Latin America and the Caribbean: Comparative Perspectives (organizers Rafael José de Menezes Bastos and Jean-Michel Beaudet). Ms.

.1995. "Esboço de uma teoria da música: para além de uma antropologia sem música e de uma musicologia sem homem". Anuário Antropológico, 1993:9-73.

1996. "Música nas terras baixas da América do Sul: ensaio a partir da escuta de um disco de música xikrín". Anuário Antropológico, 1995:251-263.

. 1999a [1978]. A musicológica kamayurá: para uma antropologia da comunicação no Alto-Xingu. Florianópolis: Editora da Universidade Federal de Santa Catarina.

. 1999b. “Music, number and man: theoretical and methodological points towards the study of music in Lowland South America". Paper presented at the Department of Ethnomusicology, Musée del' Homme, Paris 1/25/1999, by invitation of the French Ethnomusicological Society and CNRS's Laboratoire of Ethnomusicology. Ms.

2001. "Ritual, história e política no Alto Xingu: observações a partir dos Kamayurá e do estudo da festa da jaguatirica (Jawari)". In: Bruna Franchetto \& Michael Heckenberger (orgs.), Os povos do Alto Xingu. História e cultura. Rio de Janeiro: Editora da UFRJ. pp. 335-357.

. 2002. "Authenticity and entertainment: Ethnic Folkways Library, american ethnomusicology and the ethnic music market". In: G. Berlin \& A. Simon (orgs.), Music archiving in the world. Berlin: Werlag für Wissenschaft und Bildung. pp. 385-391. .2004a. "Estrutura seqüencial como rationale dos rituais musicais das terras baixas da América do Sul: uma hipótese de trabalho a partir do estudo do Yawari kamayurá". Comunicação apresentada no simpósio Antropologia e Estética — as Narrativas Instituintes: dos Mitos e Lendas às Telenovelas, organizado por Eduardo Diahaty de Menezes, 24 ${ }^{\mathrm{a}}$. Reunião Brasileira de Antropologia (Recife 12-15/06/2004). Ms.

. 2004b. "The Yawari ritual of the Kamayurá: a xinguano epic". In: Malena Kuss (org.), Music in Latin America and the Caribbean: an encyclopedic history (vol.1: Performing beliefs). Austin: University of Texas Press. pp. 77-99.

2005a. "Etnomusicologia no Brasil: algumas tendências hoje". In: Ângela Elisabeth Lühning \& Laila Andresa Cavalcante Rosa (orgs.), Etnomusicologia: lugares e caminhos, fronteiras e diálogos. Anais do $2^{\circ}$. Encontro Nacional da Associação Brasileira de Etnomusicologia. Salvador: Contexto. pp. 89-103.

2005b. "Brazil". In: J. Shep-

herd; D. Horn \& D. Laing (orgs.), The continuum encyclopedia of popular music of the world [vol.3: Latin America and the Caribbean]. Londres: The Continuum International Publishing Group. pp. 212-248.

. 2006a. "Música nas terras baixas da América do Sul (Primeira parte)". Antropologia em Primeira Mão, 86:5-20.

. 2006b. "Música nas terras baixas da América do Sul (Segunda parte)", Antropologia em Primeira Mão, 89:5-20.

. \& PIEDADE, Acácio Tadeu de Camargo. 1999. "Sopros da Amazônia: sobre as músicas das sociedades Tupi-Guarani". Mana. Estudos de Antropologia Social, 5(2):125-143. 
MINSKY, Marvin. 1983. "Music, mind and meaning". In: Manfred Clynes (org.), Music, mind and brain: the neuropsychology of music. New York: Plenum Press. pp. 1-19.

MONTARDO, Deise Lucy Oliveira. 2002. Através do "Mbaraka": música e xamanismo guarani. Tese de doutorado em antropologia social, Universidade de São Paulo.

\& MARTINS, Marcy F. 1996

"Proposta para uma leitura etnomusicológica do 'Tesoro de la Língua Guarani' de Montoya". Comunicação apresentada nas 6as. Jornadas Internacionais sobre as Missões Jesuíticas, Marechal Rondon. Ms.

MONTOYA, Antonio Ruiz de. 1876 [1639]. Arte vocabulario tesoro y catecismo de la lengua guarani. (3 vols.). Leipzig: B. G. Teubner.

NASCIMENTO, Romério H. Zeferino. 1998. Aspectos musicais no Tolê Fulni-ô: evidenciando a identidade étnica. Dissertação de mestrado em música, Universidade Federal da Bahia, Salvador.

NOVATI, Jorge. 1984. “El lenguaje sonoro comun al hombre y a las deidades: un estudio sobre las canciones de los 'Mataco' del Chaco Argentino". Temas de Etnomusicologia, 1:9-43.

OLIVEIRA JÚNIOR, Gerson Augusto de. 1998. Torém: brincadeira dos índios velhos. São Paulo: Annablume.

OLSEN, Dale A. 1996. Music of the Warao of Venezuela: song people of the Rain Forest. Gainesville: University Press of Florida.

OLSEN, Dale A. \& SHEEHY, Daniel E. 1998. South America, Mexico, Central America, and the Caribbean: The Garland Encyclopedia of world music. vol. 2. New York: Garland Publishing Inc.

OVERING, Joanna. 1989. "The aesthetics of production: the sense of com- munity among the Cubeo and the Piaroa". Dialectical Anthropology, 14:159-175.

PEREIRA, João J. de Félix. 1995. Morro da Saudade: a arte ñandeva de fazer e tocar flauta de bambu. Dissertação de mestrado em comunicação e semiótica, Pontifícia Universidade Católica, São Paulo.

PIEDADE, Acácio Tadeu de Camargo. 1997. Música yepamasa: por uma antropologia da música no Alto Rio Negro. Dissertação de mestrado em antropologia social, Universidade Federal de Santa Catarina, Florianópolis.

. 2004. O canto do Kawoká: música, cosmologia e filosofia entre os Wauja do Alto Xingu. Tese de doutorado em antropologia social, Universidade Federal de Santa Catarina, Florianópolis.

PINTO, Márnio Teixeira. 1997. Leipari: sacrifício e vida ritual entre os índios Arara (Caribe). São Paulo: Hucitec.

RANDEL, Don Michael. 1978. Harvard concise dictionary of music. Cambridge, Massachusetts: Harvard University Press.

ROSEN, Charles. 1994. "Explaining the obvious". In: The frontiers of meaning. New York: Hill and Wang. pp. 72-126.

RIBEIRO, Rosemary Machado. 1992. O mundo encantado pankararu. Dissertação de mestrado em antropologia, Universidade Federal de PernambuCo, Recife.

ROMANO, Isabel Cristina. 2000. Contos, cantos e encantos dos Pankararé. Dissertação de mestrado em letras e lingüística, Universidade Federal da Bahia, Salvador.

SALIVAS, Pierre. 1995. Iruntramu Antukma: la réunion sonore. L' hétérophonie Shuar. Paris: Université Paris VIII, Saint Dennis. Memória de DEA em Estéticas, Tecnologias e Criações Artísticas. 
SÁNCHEZ, Walter. 1998. "La plaza tomada. Proceso histórico y etnogénesis musical entre los Chiriguanos de Bolívia". Latin American Music Review, 19(2):218-243. . 2001. "'Sonidos', 'ruidos' y 'silencios' en las Misiones Franciscanas del Chaco Boliviano". Revista Argentina de Musicologia, 2:9-47.

SÁNCHEZ, Walter \& YANDURA, Angel. 2002. "Producción sonora y cosmología guaraní". In: La música en Bolivia de la prehistoria a la actualidad. Cochabamba: Fundación Simón T. Patino. pp. 95-143.

SANDRONI, Carlos (org.). 2006. "Etnomusicologia". Revista Anthropológicas, 17(1).

SEEGER, Anthony. 1987. Why Suyá sing: a musical anthropology of an amazonian people. Cambridge: Cambridge University Press.

SHERZER, Joel \& URBAN, Greg (orgs.). 1986. Native south american discourse. Berlin: Mouton de Gruyter.

SILVA, Domingos A. Bueno da. 1997. Música e pessoalidade: por uma antropologia da música entre os Kulina do Alto Purús. Dissertação de mestrado em antropologia social, Universidade Federal de Santa Catarina, Florianópolis. . 1999. "O Rami em uma ambiência musical de floresta: uma reflexão da interação dos sons da natureza e do ritual". Trabalho apresentado em um seminário realizado pelo MUSA/ PPGAS/ UFSC. Ms.

SMITH, Richard Chase. 1977. Deliverance from chaos for a song: a social and religious interpretation of the ritual performance of amuesha music. Tese de doutorado em antropologia, Cornell University, Ithaca.
SNYDER, Bob. 2000. Music and memory: an introduction. Cambridge/ Massachusetts: The MIT Press.

TRAVASSOS, Elizabeth. 1984. Xamanismo e música entre os Kayabí. Dissertação de mestrado em antropologia social, Museu Nacional, Rio de Janeiro.

TUGNY, Rosangela P. de \& QUEIROZ, Ruben C. de (orgs.). 2006. Músicas africanas e indígenas no Brasil. Belo Horizonte: Editora da Universidade Federal de Minas Gerais.

TURNER, Terence. 1993. "Imagens desafiantes: a apropriação kayapó do vídeo". Revista de Antropologia, 36:81-121.

VEIGA, Manuel. 1981. Toward a brazilian ethnomusicology: amerindian phases. Ph. D. dissertation in music, University of California at Los Angeles.

VELTHEM, Lúcia Hussak van. 2003. O belo e a fera: a estética da produção e da predação entre os Wayana. Lisboa: Assírio \& Alvim.

VÉRAS, Karin Maria. 2000. A dança matipú: corpos, movimentos e comportamentos no ritual xinguano. Dissertação de mestrado em antropologia social, Universidade Federal de Santa Catarina, Florianópolis.

VIVEIROS DE CASTRO, Eduardo. 1986. Araweté: os deuses canibais. Rio de Janeiro: Jorge Zahar Editor. 2002. "Entrevista com Eduardo Viveiros de Castro" (concedida a Rafael José de Menezes Bastos e Carmen Rial). Ilha, 4(2):113-129.

WERLANG, Guilherme. 2001. Emerging peoples: marubo myth-chants. Tese de doutorado em antropologia social, University of Saint Andrews. 


\section{Resumo}

Durante os últimos trinta anos, a etnomusicologia das terras baixas da América do Sul experimentou um forte crescimento. $\mathrm{O}$ fato está contribuindo para que a região venha a deixar de ser, definitivamente, uma das mais desconhecidas do planeta quanto às suas músicas, embora detentora de algumas das descrições mais antigas do mundo sobre música "primitiva". Um número importante de monografias e outros tipos de textos foram produzidos no período sobre a etnomusicologia da área, especialmente no Brasil e a partir de 1990, assim como tentativas de comparação regionais e sub-regionais. Também uma quantidade significativa de monografias e estudos comparativos sobre a região, feitos durante o período por antropólogos com outras especializações que não a etnomusicológica, apontou para a música em conexão típica com as demais artes, a cosmologia, o xamanismo e a filosofia como um domínio cujo conhecimento é estratégico para a compreensão da região. O quadro resultante desses esforços é promissor e está necessitando de análise, tarefa fundamental na direção da projeção de novas pesquisas. Este texto, dividido em duas partes, aproxima tal tarefa, centrando-se na produção escrita. Somente de passagem ele leva em conta as produções fonográfica, videográfica e similares. Na primeira parte do texto, levanto a literatura produzida no período sobre a música na região, assim como suas características. $\mathrm{Na}$ segunda, com base na literatura reconhecida, reflito sobre as principais marcas da música, e lanço hipóteses de trabalho para investigações futuras.

Palavras-chave: Terras baixas da América do Sul, Música e ritual, Cosmologia e filosofia, Etnomusicologia indígena

\section{Abstract}

The last thirty years have seen a remarkable growth in the ethnomusicology of the South American lowlands. The region has emerged from relative obscurity - a state in which it languished for decades, despite possessing some of the world's oldest descriptions of 'primitive' music - through the publication of a wide variety of texts on the musical production of its indigenous peoples, along with various attempts at regional and sub-regional comparison. This ethnomusicological output - much of it originating in Brazil from the early 1990s onwards - has been complimented by monographs and regional comparative studies from anthropologists specialized in other areas, whose work has frequently highlighted the importance of music (typically in connection with other art forms, cosmology, shamanism and philosophy) for a clearer understanding of the region. The resulting panorama is promising. However it also requires analysis, a fundamental element in determining paths for future research. Divided into two parts, the article approaches this endeavour by focusing on written production, making secondary use of phonographic, videographic and other documental forms. The first part of the text surveys the literature produced on the region's music over the period. In the second part, I reflect on the main features of indigenous music to emerge from the literature and propose a number of working hypotheses for future investigations.

Key words: South American lowlands, Music and ritual, Cosmology and philosophy, Indigenous ethnomusicology 